\title{
PERANCANGAN SISTEM INFORMASI DATA STOCK CONTROLLING DENGAN METODE EOQ
}

\author{
Riskian Tahmid ${ }^{1}$, Fajrul Islami ${ }^{2}$, Mutiana Pratiwi ${ }^{2}$, Ulya Ilhami Arsyah ${ }^{4}$ \\ Universitas Putra Indonesia YPTK Padang \\ E-mail: riskiantahmid@gmail.com¹,fajrul_islami@upiyptk.ac.id² ${ }^{2}$, mutiana_pratiwi@upiyptk.ac.id ${ }^{3}$, \\ ulyailhami1991@gmail.com ${ }^{4}$
}

\begin{abstract}
Information thecnology development is quickly even in outlying places that are never feeld its benefit before, but nowdays they can deeply enjoy able with information thecnology serves in an online manner. The business are established and progressed usually organized their supply management there (in the business). Previously PT. MUTIA MULIA PADANG has difficulty in the supply of the management be cause of manual character. Controlling inventory or inventory management right is not easy. But if too little inventory results in the risk of inventory shortage, as they often can not be imported goods inventory stating sudden cessation of the production process, delays in profits, even loss of customers. It would require an inventory application to manage inventory control, then the company's needs will be met with swift and precise, so as to control inventory. With the report in the form of file storage can allow minimize the potentially fatal errors, such as losing records. This application is built using the programming language PHP and MySQL, which assisted with modeling UML (Unified Modeling Language).
\end{abstract}

Keywords: Inventory System, Php, Uml (Unified Modeling Language

\section{PENDAHULUAN}

Perkembangan informasi teknologi sangat pesat bahkan di pelosok-pelosok yang dulunya belum merasakan teknologi pun sekarang bisa menikmati layanan informasi teknologi secara online. Teknologi informasi muncul sebagai akibat semakin merebaknya globalisasi dalam kehidupan organisasi, semakin kerasnya persaingan bisnis, semakin singkatnya siklus hidup barang dan jasa yang ditawarkan, serta meningkatnya tuntutan selera konsumen terhadap produk dan jasa yang ditawarkan. Untuk mengantisipasi semua ini, perusahaan mencari terobosan baru dengan memanfaatkan teknologi. Teknologi diharapkan dapat menjadi fasilitator dan interpreter. Semua teknologi informasi digunakan hanya terbatas pada pemrosesan data. Dengan semakin berkembangnya teknologi informasi tersebut, hampir semua aktivitas organisasi saat ini telah dimasuki oleh aplikasi dan otomatisasi teknologi informasi.

Perusahaan yang sudah mapan dan maju biasanya sudah bisa mengatur manajemen pengolahan data stok pada perusahaan. Sebelumnya pada PT. Mutia Mulia padang masih kesulitan dalam memanajemen persedian Stock Ban dikarenakan masih bersifat manual. Mengendalikan 

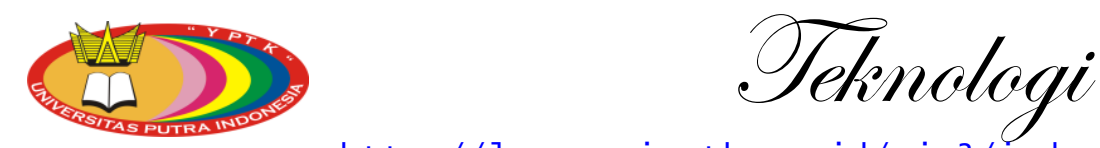

http://7ppm.upiyptk.ac.id/ojs3/index.php/TEKNOLOGI

Vol. 8 Issue 22018 Hal 1-8

ISSN: 2301-4474| e-ISSN: 2541-1535

persediaan atau inventory menagement yang tepat bukanlah hal yang mudah. Apabila jumlah persediaan terlalu besar mengakibatkan timbulnya dana yang dikeluarkan terlalu besar,meningkatnya biaya penyimpanan (seperti biaya pegawai, biaya operasional, pabrik, biaya gedung, dll) dan resiko kerusakan barang yang lebih besar. Namun bila persediaan terlalu sedikit mengakibatkan resiko terjadinya kekurangan persediaan (stock out) karena sering kali barang persediaan tidak dapat didatangkan secara mendadak yang menyatakan terhentinya proses produksi, tertundanya keuntungan, bahkan hilangnya pelanggan.

Economic Order Quantity (EOQ), adalah model manajemen persediaan yang dapat meminimumkan total biaya. Economic Order Quantity (EOQ), bertujuan dalam mempertimbangkan baik biaya-biaya operasi maupun biaya-biaya finansial seminimal mungkin serta dapat diketahui jumlah pembelian barang paling ekonomis pada setiap kali pembelian. Dalam melakukan pengendalian stock barang menjadi lebih optimal untuk tahun berikut dari data tahun sebelumnya dan juga dapat menghitung berapa stock yang aman dalam melakukan pemesanan kembali (Menurut: Tomi Lukman dan Diana Trivena dalam jurnalnya "Penarapan Metode EOQ dan ROP").

\section{LANDASAN TEORI}

\subsection{Konsep Dasar Sistem Informasi}

Dalam kehidupan sehari-hari di era teknologi dan komputerisasi saat ini, kita sering mendengar istilah mengenai sistem. Bahkan disadari maupun tidak, kita sering menggunakan atau memanfaatkan layanan yang diberikan oleh sistem tersebut. Kita juga terbantu dengan adanya sistem tersebut. Begitu juga dengan informasi, setiap hari kita selalu mendengar informasi. Informasi ini dapat kita peroleh baik di media cetak seperti (koran, majalah buku) maupun media elektronik (internet, televisi, radio).

\subsubsection{Pengertian Sistem}

Menurut I Putu Eka Pratama, (2014:7) Sistem didefinisikan sebagai kumpulan prosedur yang saling berkaitan dan saling terhubung untuk melakukan suatu tugas bersama-sama. Secara garis besar, sebuah sistem terdiri dari tiga komponen utama. Ketiga komponen tersebut mencangkup software, hardware, dan brainware. Ketiga komponen tersebut saling berkaitan. 

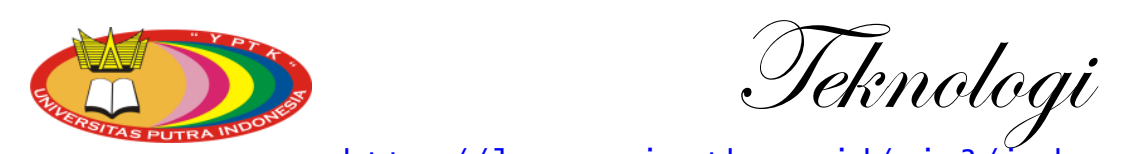

http://7ppm.upiyptk.ac.id/ojs3/index.php/TEKNOLOGI

Vol. 8 Issue 22018 Hal 1-8

ISSN: 2301-4474| e-ISSN: 2541-1535

\subsubsection{Pengertian Informasi}

Menurut I Putu Eka Pratama, (2014:9) Informasi merupakan hasil pengolahan data dari satu atau berbagai sumber, yang kemudian diolah, sehingga memberikan nilai, arti dan manfaat. Proses pengolahan data ini memerlukan teknologi baik teknologi seperti komputer maupun hanya mesin ketik.

\subsubsection{Pengertian Sistem Informasi}

Menurut I Putu Eka Pratama, (2014:10) Sistem informasi merupakan gabungan dari empat bagian utama. Keempat bagian utama tersebut mencakup perangkat lunak (software), perangkat keras (hardware), infrastruktur, dan Sumber Daya Manusia (SDM) yang terlatih.

\section{ANALISA DAN PERANCANGAN}

\subsection{Analisa Sistem}

Analisa sistem dilakukan dengan tujuan untuk mengetahui kelemahan-kelemahan yang terjadi pada sistem yang sedang berjalan atau sistem lama, karena dengan dilakukan analisa sistem yang sedang berjalan akan dapat memberikan kemudahan didalam melakukan perancangan dan pengembangan terhadap sistem yang akan dibangun.

\subsection{Perancangan Sistem Menggunakan UML}

Aplikasi ini dirancang menggunakan alat bantu berupa UML (Unified Modelling Language) agar mempermudah memindahkan konsep sistem yang dirancang ke dalam bentuk program, dimana perancangan nya digambarkan dalam bentuk diagram-diagram berikut:

\section{Use Case Diagram}

Use case diagram digunakan untuk menggambarkan kegiatan-kegiatan yang terdapat dalam sebuah sistem dalam menghubungkan interaksi antara aktor dengan sebuah sistem. 

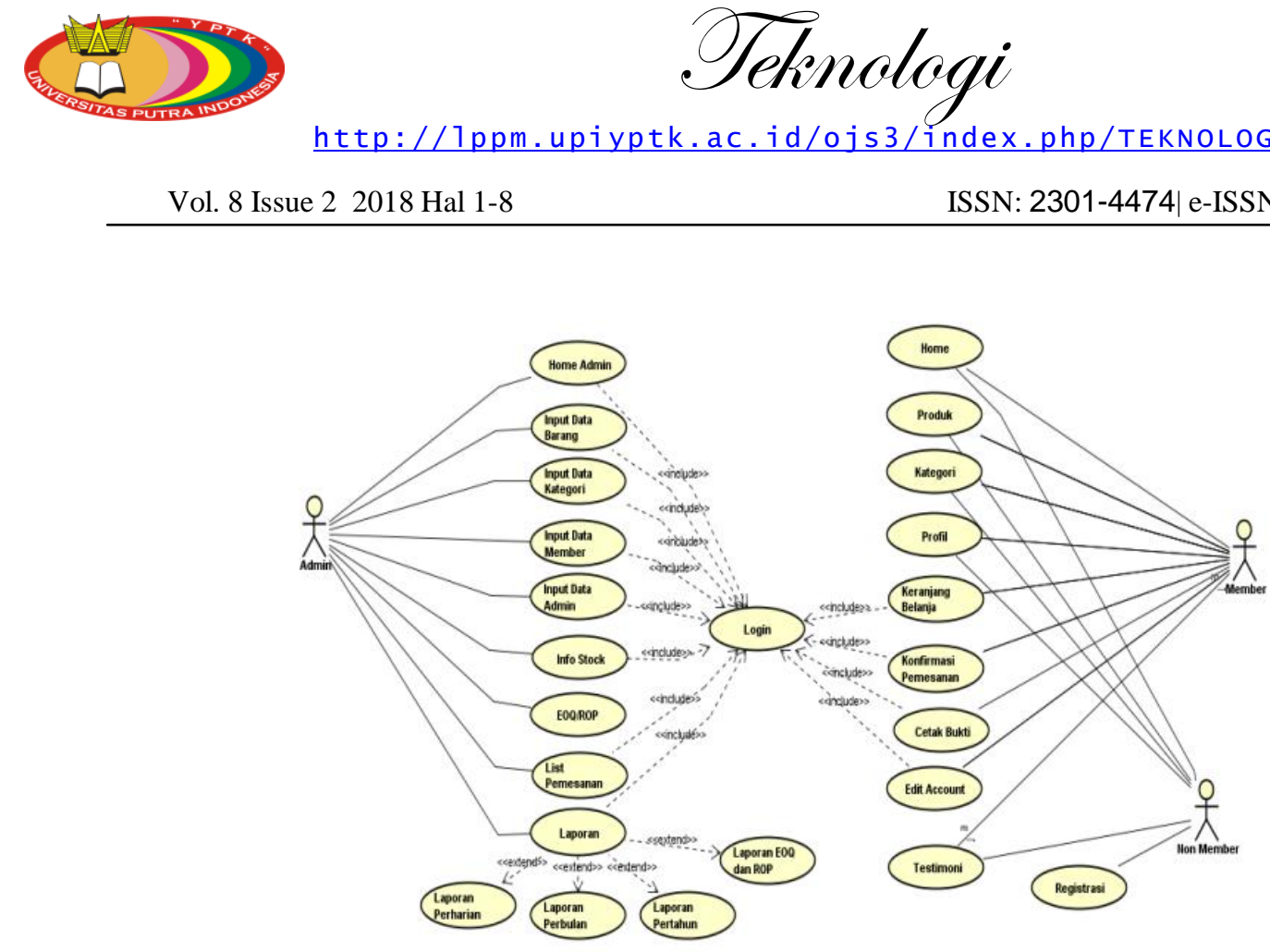

Gambar 1.1 Use Case Diagram

\subsubsection{Class Diagram}

Class Diagram digunakan untuk sebuah spesifikasi yang jika diintansiasi akan menghasilkan sebuah objek dan merupakan inti dari pengembangan dan desain beriorentasi objek.

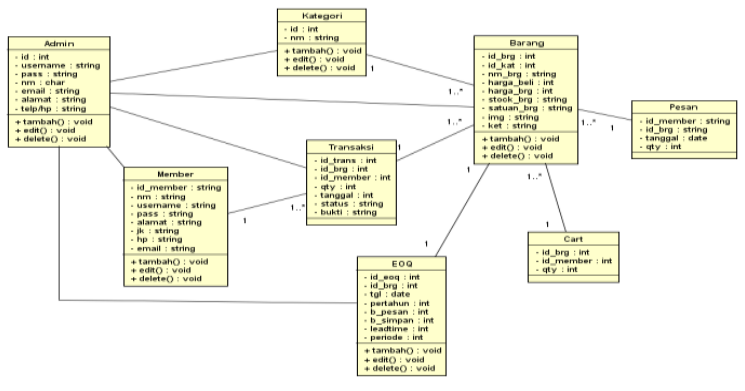

Gambar 3.1 Class Diagram 


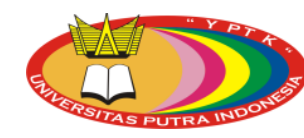

\section{IMPLEMENTASI SISTEM}

\subsection{Implementasi Sistem}

Penerapan aplikasi pemesanan dan pengendalian stock barang pada Toko Bangunan Andria.

\subsection{Tampilan Login}

Disini terlihat form login yang digunakan untuk keamanan sistem, untuk dapat masuk ke sistem informasi pengolahan stock pada PT. Mutia Mulia kita harus mengentrikan username dan password seperti Gambar 4.2.

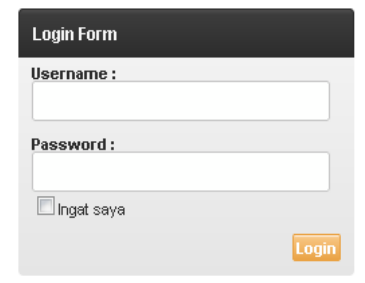

\section{Gambar 4.2 Login User}

\subsection{Tampilan Menu Utama}

Disini terlihat beberapa menu pada Menu utama yaitu menu Entry, Transaksi, Laporan, Analisa Eoq, dan Logout. seperti Gambar 4.3

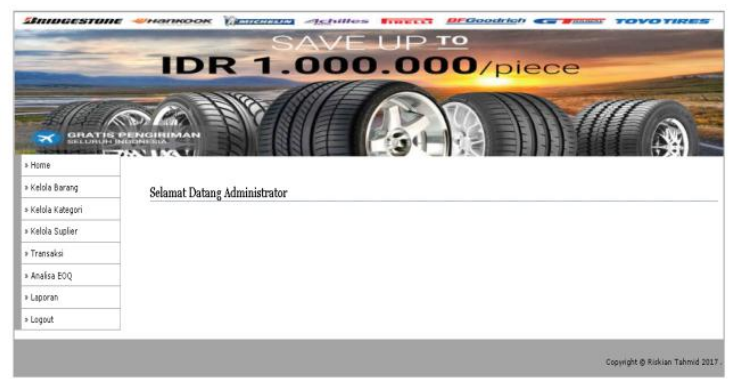

Gambar 4.3 Tampilan Home Member 


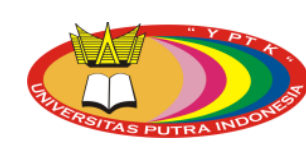

\subsection{Tampilan Analisa EOQ dan ROP}

Halaman data analisa EOQ dan ROP ini digunakan untuk menganalisa untuk pemesanan berikutnya. Berikut gambar tampilan analisa eoq dan rop dapat dilihat pada gambar 4.4 berikut ini:

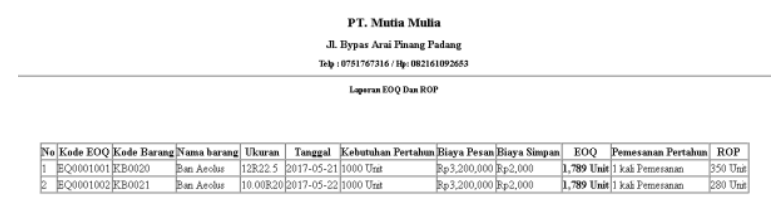

\section{Gambar 4.4 Tampilan Analisa EOQ dan ROP}

\section{KESIMPULAN}

Dari penelitian dan pembahasan yang telah penulis lakukan, maka dapat disimpulkan beberapa hal sebagai berikut :

1. Dengan menggunakan sistem aplikasi pengolahan data persediaan barang, maka kebutuhan perusahaan dapat terpenuhi dengan cepat dan tepat, sehingga dapat mengontrol persediaan barang.

2. Peranan sistem komputerisasi mempunyai nilai tambah dalam pengolahan data persediaan, sertaakan meningkatkan efisiensi dan efektivitas dalam persediaan barang.

3. Dengan adanya penyimpanan laporan dalam bentuk file dapat meminimalisir terjadinya kesalahan yang cukup fatal seperti kehilangan arsip, disamping itu dapat lebih mudah dicari jika dibutuhkan kembali.

Selama ini proses pengolahan data pada PT. Mutia Mulia dilakukan dengan cukup baik, meskipun demikian sebuah sistem tak akan ada yang benar-benar sempurna yang ada hanya menuju kepada kesempurnaan. Oleh karena itu perlu diadakan evaluasi dan perbaikan terusmenerus yang sifatnya meningkatkan kinerja dari sistem pengolahan data ini serta bisa menjadi bahan acuan pengembangan lebih lanjut. Karenanya dalam kesempatan ini penulis menyarankan :

1. Sistem pengolahan data persediaan melalui alat bantu komputer harus didukung oleh tenaga yang mengerti tentang komputer.

2. Perlu adanya penyesuaian oleh pemakai sistem baru yang dengan tujuan agar terciptanya keselarasan antara pemakai dengan sistem yang baru sehingga hasil yang diinginkan dapat dipenuhi. 

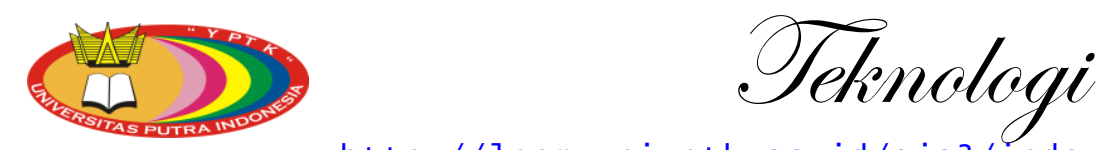

http://1ppm.upiyptk.ac.id/ojs3/index.php/TEKNOLOGI

Vol. 8 Issue 22018 Hal 1-8

ISSN: 2301-4474| e-ISSN: 2541-1535

3. Sistem ini masih jauh dari kesempurnaan dan masih banyak terdapat kekurangan, diharapkan bagi pengembang selanjutnya dapat mengembangkan aplikasi ini lebih baik dari sebelumnya.

Dari saran-saran di atas, diharapkan sistem informasi yang baru ini dapat bermanfaat bagi pihak-pihak yang berniat untuk melakukan pengembangan lebih lanjut, khususnya PT. Mutia Mulia sendiri agar hasil yang dicapai bisa lebih maksimal dan optimal.

\section{DAFTAR PUSTAKA}

A.S , Rosa. 2014. Rekayasa Perangkat Lunak. Bandung : Informatika.

Difana Meilani, Ryan Eka Saputra 2013. Pengendalian Persediaan Bahan Baku Vulkanisir Ban (Study Kasus: PT. Gunung Pulo Sari) : Optimasi Sistem Industri ISSN 2088-4842.

Dina Rahmayanti, Ahmad Fauzan 2013. Optimalisasi Sistem Persediaan Bahan Baku Karet Mentah(Lateks) dengan Metode Lot Sizing(Studi Kasus : PT. Abisiat Raya): Optimasi Sistem Persediaan: ISSN : 2088-4842

Ida Bagus Manik Brahmandhika, Ratna Komala Dewi, I Ketut Suamba 2016. Analisis Pengendalian Persediaan Bahan Baku Tauco di Perusahaan Kecap Manalagi Kota Denpasar Provinsi Bali: E-Jurnal Agribisnis dan Agrowisata Vol. 5, No. 3, Juli 2016 ISSN: 2301-6523.

I Komang Setia Buana. 2014. Sistem Teknologi Informasi. Yogyakarta : Penerbit Andi Offset.

I Putu Agus Eka Pratama. Sistem Informasi dan Implementasinya. Bandung : Penerbit Informatika.

Kadir, Abdul. 2014. Pengenalan Sistem Informasi (Edisi Revisi, Andi Offset, Yogyakarta) Muzayyanah, I Ketut Suyamba, Ratna Komala Dewi 2015. Analisis Pengendalian Persediaan Bahan Baku Biji Kakao pada Pabrik Delicacao Bali di Kabupaten Tabanan: E-Jurnal Agribisnis dan Agrowisata ISSN : 2301-6523.

Reza Abdurrofi, Magdalena Karismariyanti 2016. Aplikasi Untuk Optimasi Persediaan Bahan Baku Menggunakan Model Economic Order Quantity (Eoq) Pada 
Pabrik Tahu di Jawa Barat: Seminar Nasional Teknologi Informasi dan Multimedia 2016 ISSN : 2302-3805.

Priyanto Hidayatullah, Jauhari Khairul Kawistara. 2014. Analisis \& Desain. Yogyakarta : Penerbit Andi Offset. 